\title{
Social inequalities in fatal childhood accidents and assaults: England and Wales, 2001-03
}

Veronique Siegler and Alaa Al-Hamad Office for National Statistics and David Blane Imperial College, London

\section{Abstract}

\section{Background}

This article presents age-specific mortality rates of children for selected causes of accidents and assault using the National Statistics Socio-economic Classification (NSSEC). The study is an analysis of the social inequalities in fatal childhood accidents and assault at the start of the 21 st century. It aims to identify the causes and age groups for which these inequalities are the widest.

\section{Methods}

In order to classify children by NS-SEC, the most advantaged class of the biological or adoptive parents was used. Death registrations provided the number of deaths from accidents and assault for children aged from 28 days to 15 years, in England and Wales, between 2001 and 2003. The population of children by NS-SEC and age group was obtained from the 2001 Census. Age-specific mortality rates were estimated. Inequalities were measured using socio-economic gradients in mortality.

\section{Results}

There were wide social inequalities in fatal accidents and assaults for children aged between 28 days and 15 years. The overall mortality rate in the routine class was 64 per million children aged up to 15, 4.5 times the rate of children with parents in the higher managerial and professional class. The greatest inequalities in accidental mortality for children in that age group were observed for fire and pedestrian accidents, followed by accidental suffocation. Infants at least 28 days but less than one year were subject to the widest inequalities of all age groups in fatal accidents and assault. The highest mortality rate in this study resulted from assault on babies whose parents could not be classified by occupation.

Pedestrian and other transport accidents were the greatest causes of death for children between 5 and 15 years old. Inequalities were much larger for pedestrian than for other transport accidents for children aged 14 years and under. 
The leading cause of death for children aged less than five years was suffocation, followed by drowning and exposure to fire/hot substances. In that age group, the risk of death from exposure to fire was significantly higher for children whose parents could not be classified by occupation.

\section{Conclusions}

Substantial social inequalities in childhood mortality from accidents and assault existed in 2001-03. Reducing the large inequalities between the most advantaged class and the most disadvantaged group in the non-occupied category, would make a substantial impact on childhood deaths from accidents and assaults. If the mortality rates in the latter group were the same as in the most advantaged managerial and professional class, deaths of infants of at least 28 days but less than one year, from assault would be reduced by 62 per cent. Deaths from fire, accidental suffocation and pedestrian accidents in the under fives would be reduced by 50 per cent, 25 per cent and 28 per cent respectively. Deaths in pedestrian and transport accidents for children aged 5-15 would be reduced by 25 per cent and 16 per cent respectively. 


\section{Contents}

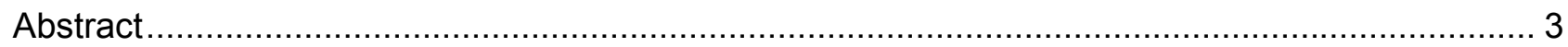

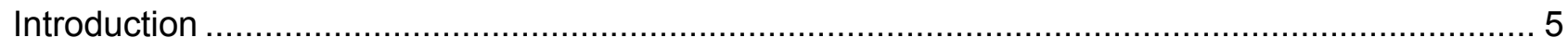

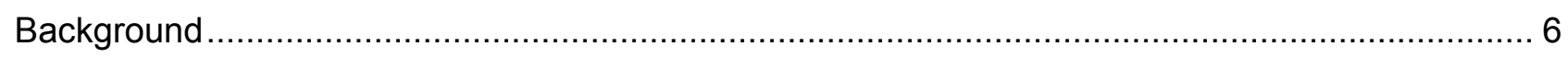

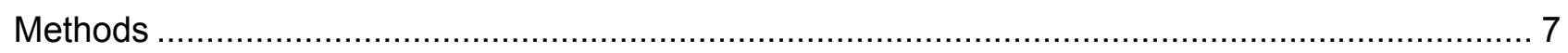

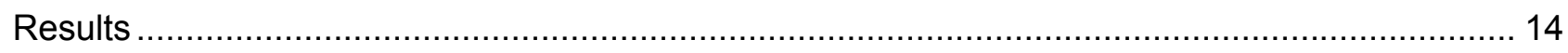

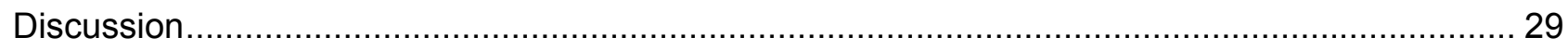

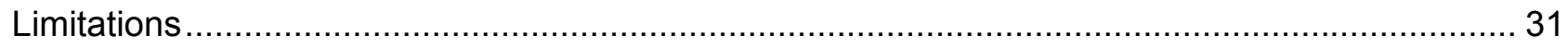

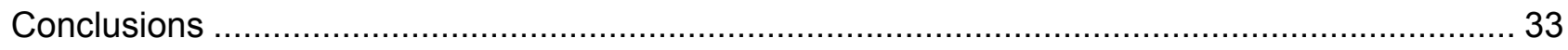

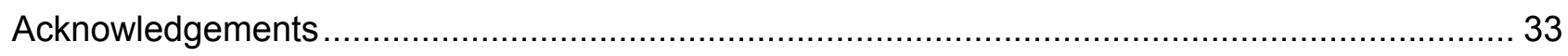

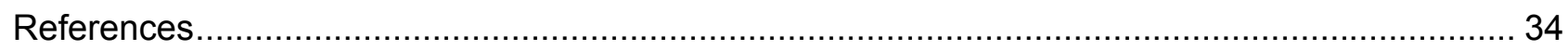

\section{List of Figures}

Figure 1 Age specific mortality rates from all accidents by NS-SEC and age group, children

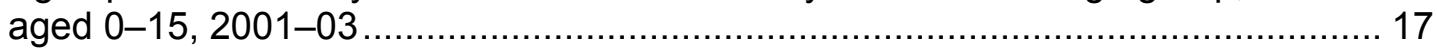

Figure 2 Age-specific mortality ratios from all accidents by age group, children aged 0-15, 2001-03

Figure 3 Age-specific mortality rates from selected causes of accident and assault, by NSSEC, children aged $0-15,2001-03$

Figure 4 Age-specific mortality ratios from selected causes of accidents and assault, children aged $0-15,2001-03$. 


\section{List of Tables}

Table 1 Population of children: by age group and NS-SEC of biological and adoptive

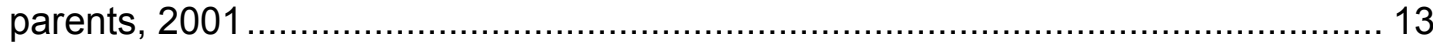

Table 2 Accidental deaths of children: by age group and cause of death, 2001-03 ........... 14

Table 3 Age-specific mortality rates of children from all accidents: by NS-SEC and age

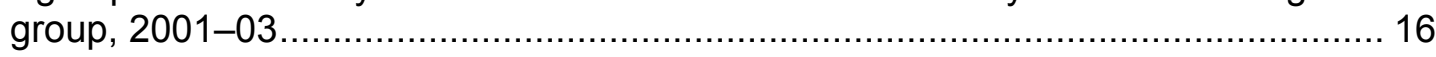

Table 4 Age-specific mortality rates from selected causes: by NS-SEC, children aged 0-15, 2001-03.

Table 5 Age-specific mortality rates of children from all accidents, pedestrian and transport accidents: by 'reduced NS-SEC' and age group, 2001-03................................. 24

Table 6 Age-specific mortality rates of children from all accidents and accidents caused by falls, drowning or exposure to fire/hot substances: by 'reduced NS-SEC' and age

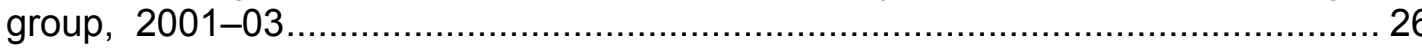

Table 7 Age-specific mortality rates of children from all accidents, accidental suffocation, and assault, by 'reduced NS-SEC' and age group, 2001-03 ...................................... 28

\section{Introduction}

Accidents and assaults are major causes of avoidable mortality in children. A Department of Health report (2002) highlighted accidental injury as a leading cause of child death in England and Wales, resulting in the deaths of over 1000 children aged under 15 years in 1998-2000. Furthermore, accidental mortality among children was reported to have a strong inverse relationship with social class. Assault is a relatively uncommon cause of death, but mortality rates for infants under the age of one year have been reported as being higher than in any other age group (Rooney and Devis, 1999).

This article reports on social inequalities in childhood mortality due to accidents and assaults in England and Wales, 2001-03. The focus is on children from the postneonatal period (at least 28 days but under one year old) to the age of 15 years. The paper uses the National Statistics Socioeconomic Classification (NS-SEC) of the child's biological or adoptive parents to analyse mortality rates for selected types of accidents and for assaults.

\section{Background}

The Black Report (1980) highlighted accidents as one of the most important causes of death among children aged between 1 and 14 years, and also one of the drivers of differences in mortality rates between Registrar General social classes I and V. The report identified accidents in the home as an area where major progress could be made quickly, but recognised that action to improve the environment outside the home was also important. The Registrar General's Decennial Supplements (OPCS, 1970-72 and 1979-80, 1982-83) have acknowledged accidental death as one of the causes of childhood mortality with the steepest socio-economic gradient. 
In 1999 the White Paper 'Saving Lives: Our Healthier Nation' made injury prevention a Government priority and set national targets to reduce the rates of accidental death and serious accidental injuries. At the time, the paper highlighted accidental injury as a leading cause of death among children. The paper also emphasised that accidental injury was responsible for more children being admitted to hospital each year than any other cause. The Department of Health, (2002) produced a report entitled 'Preventing Accidental Injury: Priorities for Action' which advised on strategies and programmes that could help to reduce accidental death rates and serious injuries from accidents. In this report, traffic and pedestrian injuries were highlighted as the main causes of accidental death for children aged between 0 and 14 years in England in 2000. English children in the 10 per cent most deprived wards were shown to be more than three times as likely to be pedestrian casualties as those in the 10 per cent least deprived wards (Grayling, 2002).

World Health Organisation (WHO) statistics (Galan and Farchi, 2007), also identified the leading cause of accidental deaths in children and adolescents aged between 0 and 19 years in the European Region in 2002 as being road traffic injuries (37 per cent of accidental deaths). Other causes included drowning ( 15 per cent), poisoning ( 8 per cent), falls ( 5 per cent), fires (4 per cent) and other unintentional injuries (31 per cent).

The independent Audit Commission report 'Better safe than sorry - preventing unintentional injury to children' (2007) acknowledged that although the accidental mortality rates of children were declining, unintentional injury was still a leading cause of death and hospital admission for children aged between one and 14 years. The report also highlighted that inequalities in accidental death for children in different socio-economic groups were persistent and broadening. This report concluded that 'unintentional injury has struggled to be a priority for many organisations' and made further recommendations on possible improvements on national and local levels.

Assault has also been highlighted as having a strong relationship with deprivation (Bellis et al., 2008). Bellis et al. in their 2002-06 study found that higher rates of hospital admissions due to assault were associated with deprivation across all ages. Those aged 14 years and under residing in the poorest quintile in England had a rate of hospital admission due to assault six times higher than those in the least deprived quintile.

This article contributes to the debate on social inequalities in childhood accidents and assaults by presenting mortality rates for the period of 2001-03 for selected childhood accidents and for assaults. These rates will be presented according to the National Statistics Socio-economic Classification (NS-SEC) of the children's biological or adoptive parents in order to assess differences that exist between socio-economic groups.

\section{Methods}

This section describes the NS-SEC in more detail, specifies the data sources used in the analysis and describes the outcome measures adopted in this article.

\section{The National Statistics Socio-economic Classification (NS-SEC)}

The conceptual basis for the NS-SEC, as developed by Rose and Pevalin (2003), is the structure of employment relations operating in modern developed economies. Occupations are differentiated 
in terms of reward mechanisms, promotion prospects, autonomy and job security. The most advantaged NS-SEC classes (higher managerial and professional), typically exhibit personalised reward structures, have good opportunities for advancement, relatively high levels of autonomy within the job, and are relatively secure. These attributes tend to be reversed for the most disadvantaged class (routine). 


\section{Box 1 National Statistics Socio-economic Classification Analytic classes}

Eight class version

1.1 Large employers and higher managerial

$1.2 \quad$ Higher professional

2 Lower managerial and professional

$3 \quad$ Intermediate

$4 \quad$ Small employers and own account workers

$5 \quad$ Lower supervisory and technical

6 Semi-routine

$7 \quad$ Routine

Non-occupied
Analytic classes
Examples of occupations include

Senior officials in national and local government; directors and chief executives of major organisations; officers in the armed forces

Civil engineers, medical practitioners, physicists, geologists, IT strategy and planning professionals, legal professionals, architects

Teachers in primary and secondary schools, quantity surveyors, public service administrative professionals, social workers, nurses, IT technicians

NCOs and other ranks in the Armed Forces, graphic designers, medical and dental technicians, local

government clerical officers, counter clerks

Hairdressing and beauty salon proprietors, shopkeepers, dispensing opticians in private practice, farmers, self-employed taxi drivers

Bakers and flour confectioners, screen-printers, plumbers, electricians and motor mechanics employed by others, gardeners, rail transport operatives

Pest control officers, clothing cutters traffic wardens, scaffolders, assemblers of vehicles, farm workers, veterinary nurses and assistants, shelf fillers

Hairdressing employees, floral arrangers, sewing machinists, van bus and coach drivers, labourers, hotel porters, bar staff, cleaners and domestics, road sweepers, car park attendants

Never worked, Long-term unemployed, Full time students, and Unclassified for other reasons Occupation inadequately described
Three class version

1 Professional and managerial occupation
2 Intermediate occupations
3 Routine and manual occupations
Non-occupied

The NS-SEC category is derived from an individual's occupation and employment status and the size of their organisation. Since size of organisation is not collected on the death register, a version of NS-SEC is used which is derived from occupation and employment status alone. This version of the NS-SEC is known as 'reduced NS-SEC' and is used throughout the following analysis.

NS-SEC is nested so that the operational categories can offer maximum flexibility in terms of the different collapses possible (within the underlying conceptual model of employment relations). Box 
1 presents the eight and three class versions of the NS-SEC and shows how they are related (Rose and Pevalin, 2003).

For the purpose of this paper, those who had never worked, the long-term unemployed, full-time students, those with an occupation inadequately described and unclassified for other reasons are referred to as the non-occupied group. This latter class is not deemed to be a specific NS-SEC class (being composed of a disparate range of people).

On the death of a child, relatives (usually one or both parents) will register the death. Previously, for analysis purposes, the father's social class was always used if the father was present, and the mother's only if the father was absent. Owing to women's increased participation in the labour market in recent years, it was thought to be most appropriate to use a 'combined' classification where the most advantaged of the biological or adoptive parent's NS-SEC class was used to represent the child's socio-economic class.

The 'combined' classification method is a variant of Erikson's 'dominance' rule (Erikson, 1984), where a member of a household is classified by the person in the household who is 'dominant' in the labour market. The 'combined' classification has been used previously in an analysis describing social inequalities in adult female mortality (Langford and Johnson, 2009). So for example, if the mother is classified to a routine occupation (NS-SEC class 7) and the father is selfemployed (NS-SEC class 4), then any children would be deemed to belong to NS-SEC class 4.

\section{Data Sources for analysis}

Two sources were used to extract the data needed to calculate the mortality rates by NS-SEC, reported in this article. Death registrations were used to determine the numerators and the 2001 Census was used to produce population estimates for the denominators. 


\section{Death registrations}

Death registration records were used to identify accidental and assault related deaths of children from postneonatal (at least 28 days but under one year) to age 15 years, registered in England and Wales in the calendar years 2001 to 2003 . It was assumed that the parents whose details were recorded on the death certificate were the biological or adoptive parents, not step-parents or foster carers. Accidental deaths were identified using the International Classification of Diseases, 10th revision (ICD-10). Box 2 lists the ICD-10 codes used to extract the mortality data reported in this article. Causes of death were grouped to ensure sufficiently large numbers for robust statistical analysis when broken down by age group, NS-SEC, and selected accidents.

\section{Box 2 Causes of death included in the analysis}

CAUSE OF DEATH

All accidents

Pedestrian accidents

Transport accidents excluding Pedestrian

Falls

Accidental drowning and submersion

Fire/flame, exposure to hot objects/substances

Suffocation

Other accidents

Assault

$\begin{array}{rr}\text { ICD 10 CODE } & \text { Deaths (\%) } \\ \text { V01-V99;W00-W99 } & 1016(100) \\ \text { X00-X59;Y85;Y86 } & 228(22) \\ \text { V01-V09 } & 307(30) \\ \text { V10-V99; Y85 } & \\ \text { W00-W19 } & 42(4) \\ \text { W65-W74 } & 96(9) \\ \text { X00-X19 } & 97(10) \\ \text { W75-W84 } & 174(17) \\ \text { W20-W64;W85-W99; } & 72(7) \\ \text { Y86;X20-X59 } & 164 \\ \text { X85-X99; Y00-Y09; } & \\ \text { Y100-Y349 where } & \\ \text { mdth10=014 } & \end{array}$

Deaths resulting from assaults were more difficult to identify. In England and Wales, up to half the deaths eventually classified as assault (X85-Y09) may not appear as such in the original annual data. Deaths being investigated and registered before the cause can be certified fully are assigned a temporary underlying cause code and a manner of death code indicating that the verdict is still 'pending investigation' (Rooney and Davis, 1999). Therefore the 242 cases identified in this current study (in 2001-03) as assault with verdict pending were investigated further to determine their 
status at the time of the current analysis. The results showed that 68 per cent of the cases investigated were classified as assault, 9 per cent were ascribed to transport accidents (and transferred to that category) and 23 per cent were reported as still pending in August 2010 and hence are excluded from this analysis.

\section{The 2001 Census}

The 2001 Census provided data on all dependent children aged 28 days to 15 years in England and Wales, classified according to the combined NS-SEC of the biological or adoptive parents. The most advantaged of the parents' NS-SEC class was used to represent the child's socio-economic position. When the child was living with one biological or adoptive parent only (children living with a single parent or in step-families) the NS-SEC class of that biological or adoptive parent was chosen to represent the socio-economic class of the child. Children not living with any biological or adoptive parents, such as those in foster placements or communal establishments $(0.2$ per cent of the total population of dependent children aged 28 days to 15 years in England and Wales) were not included in this study.

Table 1 illustrates the population of children aged 28 days to 15 years used in this analysis. The numbers presented were used as denominators in the calculation of reported mortality rates. 


\section{Table 1 Population of children: by age group and NS-SEC ${ }^{2}$ of biological and adoptive parents ${ }^{3}, 2001$}

England and Wales

Numbers

\begin{tabular}{|c|c|c|c|c|c|c|}
\hline \multirow[t]{2}{*}{ NS-SEC ${ }^{2}$} & \multicolumn{6}{|c|}{ Age group } \\
\hline & $0^{1}-1$ & $1-4$ & $5-9$ & $10-14$ & 15 & $0^{1}-15$ \\
\hline 1.1 Large employers and higher managerial & 46,367 & 204,337 & 246,449 & 226,425 & 41,422 & 765,000 \\
\hline 1.2 Higher professional & 57,543 & 238,250 & 271,193 & 248,022 & 45,216 & 860,224 \\
\hline 2. Lower managerial \& professional & 152,421 & 663,217 & 829,346 & 856,813 & 165,875 & $2,667,672$ \\
\hline 3. Intermediate & 63,102 & 280,470 & 342,247 & 342,024 & 65,097 & $1,092,940$ \\
\hline 4. Small employers \& own account & 32,948 & 179,888 & 280,612 & 309,981 & 60,066 & 863,495 \\
\hline 5. Lower supervisory and technical & 41,347 & 192,060 & 251,929 & 264,528 & 51,970 & 801,834 \\
\hline 6. Semi-routine & 62,778 & 293,184 & 389,707 & 423,831 & 80,706 & $1,250,206$ \\
\hline 7. Routine & 35,341 & 169,081 & 223,513 & 238,999 & 46,335 & 713,269 \\
\hline 'Non-occupied' 4 & 44,643 & 258,106 & 425,171 & 429,321 & 80,816 & $1,238,057$ \\
\hline Total & 536,490 & $2,478,593$ & $3,260,167$ & $3,339,944$ & 637,503 & $10,252,697$ \\
\hline
\end{tabular}

1 Deaths at age 0 only include postneonatal deaths (children at least 28 days but under one year)

2 Reduced NS-SEC based on the most advantaged NS-SEC of either biological/ adoptive mother or biological/ adoptive father 321,501 children not living with any biological and adoptive parents were not included in the population for analysis

4 'The 'Non-occupied' category includes 'never worked, long-term unemployed, full-time students, inadequately described and unclassified for other reasons'.

\section{Outcome measures:}

To compare the accidental and assault-related mortality of children belonging to different socioeconomic classes, the age-specific mortality rates by NS-SEC were calculated for the following agebands: postneonatal (babies at least 28 days but under one year old), 1-4, 5-9, 10-14 and 15 years. This measure was based on the number of child deaths in each age group and class divided by the population of children in the same age group and class at risk. Ninety-five per cent confidence intervals were constructed for the various mortality rates.

The ratios of the mortality rates of the least advantaged to the most advantaged were calculated for both the full and three-classes condensed version of NS-SEC. These are referred to in the article as socio-economic gradients. The ratios of the mortality rate of the non-occupied to the most advantaged were also calculated. Significance tests were used to assess these ratios between the least and most advantaged classes. 


\section{Results}

\section{Number of deaths from accidents and assault for children aged between 28 days and 15 years}

There were 1016 accidental deaths of children aged between 28 days and 15 years in the years 2001-03, representing 13 per cent of all deaths to children of that age in that time period. The numbers and percentages of accidental deaths by age group and by cause are reported in Table 2 .

Transport accidents excluding pedestrian accidents were the greatest overall cause of accidental death for children aged 28 days -15 years (30 per cent of all accidental deaths), followed by pedestrian accidents ( 22 per cent of all accidental deaths). The next most important cause was suffocation (17 per cent of all accidental deaths), but this was by far the most important cause among children aged 4 years and under (31 per cent of all accidental deaths). Drowning and submersion, and fire were respectively the second and third most important causes of accidental death for children aged 4 years and under (15 per cent of all accidental deaths respectively).

There were 164 deaths from assault for children aged 28 days-15 years, of which 59 per cent occurred in children under five years.

\section{Table 2 Accidental deaths of children: by age group and cause of death, 2001-03}

England and Wales

Numbers and Percentages

\begin{tabular}{|c|c|c|c|c|c|c|c|c|c|c|}
\hline \multirow[t]{3}{*}{ Cause of death } & \multicolumn{10}{|c|}{ Age group } \\
\hline & \multicolumn{2}{|c|}{$0^{1}-4$} & \multicolumn{2}{|c|}{$5-9$} & \multicolumn{2}{|c|}{$10-14$} & \multicolumn{2}{|c|}{15} & \multicolumn{2}{|c|}{$0^{1}-15$} \\
\hline & $\begin{array}{l}\text { Number } \\
\text { of deaths }\end{array}$ & Percentage & $\begin{array}{l}\text { Number } \\
\text { of deaths }\end{array}$ & Percentage & $\begin{array}{r}\text { Number } \\
\text { of deaths }\end{array}$ & Percentage & $\begin{array}{l}\text { Number } \\
\text { of deaths }\end{array}$ & Percentage & $\begin{array}{l}\text { Number } \\
\text { of deaths }\end{array}$ & Percentage \\
\hline All Accidents & 344 & 100 & 186 & 100 & 357 & 100 & 129 & 100 & 1016 & 100 \\
\hline Pedestrian accidents & 49 & 14 & 55 & 30 & 102 & 29 & 22 & 17 & 228 & 22 \\
\hline Other transport accidents & 48 & 14 & 56 & 30 & 131 & 37 & 72 & 56 & 307 & 30 \\
\hline Falls & 16 & 5 & 4 & 2 & 19 & 5 & 3 & 2 & 42 & 4 \\
\hline Drowning & 53 & 15 & 19 & 10 & 18 & 5 & 6 & 5 & 96 & 9 \\
\hline Fire/Hot substances & 50 & 15 & 27 & 15 & 17 & 5 & 3 & 2 & 97 & 10 \\
\hline Suffocation & 105 & 31 & 10 & 5 & 45 & 13 & 14 & 11 & 174 & 17 \\
\hline Other accidents & 23 & 7 & 15 & 8 & 25 & 7 & 9 & 7 & 72 & 7 \\
\hline Assault & 97 & & 33 & & 29 & & 5 & & 164 & \\
\hline
\end{tabular}

1 Deaths at age 0 only include postneonatal deaths (children at least 28 days but under one year)

Source: Death registration records 


\section{Age-specific mortality rates from all accidents by NS-SEC and age group}

The age-specific mortality rates per 1,000,000 children by socio-economic classification and by age group for all accidents are shown in Table 3 and illustrated in Figure 1. The ratios of mortality rates of children classified in NS-SEC class 7 and in the non-occupied group respectively, to that of children classified in NS-SEC class 1 are presented in Table 3 and illustrated in Figure 2. 


\section{Table 3 Age-specific mortality rates ${ }^{1,2}$ of children from all accidents: by NS-SEC and age group, 2001-03}

\begin{tabular}{|c|c|c|c|c|c|c|c|}
\hline \multicolumn{8}{|c|}{ ALL ACCIDENTS } \\
\hline \multirow{2}{*}{\multicolumn{2}{|c|}{ NS-SEC }} & \multicolumn{6}{|c|}{ Age group } \\
\hline & & $0^{3}-1$ & $1-4$ & $5-9$ & $10-14$ & 15 & $0^{3}-15$ \\
\hline \multirow[t]{2}{*}{1} & Higher managerial, professional & 13 & 13 & 13 & 15 & 31 & 14 \\
\hline & & $(5,34)$ & $(8,21)$ & $(8,20)$ & $(10,23)$ & $(15,62)$ & $(11,18)$ \\
\hline \multirow[t]{2}{*}{1.1} & Large employers, higher managers & 7 & 8 & 18 & 13 & 48 & 15 \\
\hline & & $(1,51)$ & $(3,20)$ & $(10,30)$ & $(7,25)$ & $(22,107)$ & $(11,21)$ \\
\hline \multirow[t]{2}{*}{1.2} & Higher professionals & 17 & 17 & 9 & 16 & 15 & 14 \\
\hline & & $(6,54)$ & $(10,30)$ & $(4,18)$ & $(9,28)$ & $(4,59)$ & $(10,19)$ \\
\hline \multirow[t]{2}{*}{2} & Lower managerial, professional & 26 & 10 & 10 & 22 & 54 & 18 \\
\hline & & $(15,46)$ & $(6,16)$ & $(7,15)$ & $(17,29)$ & $(37,79)$ & $(15,21)$ \\
\hline \multirow[t]{2}{*}{3} & Intermediate & 21 & 27 & 6 & 33 & 77 & 25 \\
\hline & & $(8,56)$ & $(18,41)$ & $(3,13)$ & $(24,46)$ & $(46,127)$ & $(20,31)$ \\
\hline \multirow[t]{2}{*}{4} & $\begin{array}{l}\text { Small employers, own account } \\
\text { workers }\end{array}$ & 91 & 35 & 14 & 29 & 44 & 29 \\
\hline & & $(47,175)$ & $(22,55)$ & $(8,25)$ & $(20,42)$ & $(22,89)$ & $(23,36)$ \\
\hline \multirow[t]{2}{*}{5} & Lower supervisory and technical & 97 & 33 & 15 & 29 & 45 & 30 \\
\hline & & $(55,170)$ & $(21,52)$ & $(8,26)$ & $(19,44)$ & $(21,94)$ & $(24,38)$ \\
\hline \multirow[t]{2}{*}{6} & Semi-routine & 69 & 34 & 28 & 48 & 91 & 42 \\
\hline & & $(40,119)$ & $(24,49)$ & $(20,40)$ & $(37,62)$ & $(60,138)$ & $(36,50)$ \\
\hline \multirow[t]{2}{*}{7} & Routine & 226 & 63 & 46 & 56 & 65 & 64 \\
\hline & & $(151,338)$ & $(45,89)$ & $(33,66)$ & $(41,76)$ & $(34,124)$ & $(54,75)$ \\
\hline \multirow{2}{*}{\multicolumn{2}{|c|}{ 'Non-occupied'4 }} & 217 & 99 & 38 & 73 & 136 & 76 \\
\hline & & $(151,312)$ & $(80,124)$ & $(28,50)$ & $(60,89)$ & $(97,191)$ & $(67,85)$ \\
\hline \multirow{2}{*}{\multicolumn{2}{|c|}{ All children }} & 66 & 32 & 19 & 36 & 67 & 33 \\
\hline & & $(55,80)$ & $(28,36)$ & $(16,22)$ & $(32,40)$ & $(57,80)$ & $(31,35)$ \\
\hline \multirow{2}{*}{\multicolumn{2}{|c|}{ Ratio 7:1 }} & 17.6 & 4.9 & 3.6 & 3.8 & 2.1 & 4.5 \\
\hline & & $(6.1,50.8)$ & $(2.7,8.9)$ & $(2.0,6.3)$ & $(2.2,6.4)$ & $(0.8,5.5)$ & $(3.3,5.9)$ \\
\hline \multirow{2}{*}{\multicolumn{2}{|c|}{ Ratio 'Non-occupied':1 }} & 16.9 & 7.8 & 2.9 & 4.9 & 4.4 & 5.3 \\
\hline & & $(5.9,48.0)$ & $(4.6,13.1)$ & $(1.7,4.9)$ & $(3.1,7.9)$ & $(2.0,9.6)$ & $(4.1,6.9)$ \\
\hline
\end{tabular}

1 Age-specific mortality rates along with 95 per cent Confidence Intervals shown below the rates in parenthesis 2 Figures in table are rounded to nearest integer

3 Deaths at age 0 only include postneonatal deaths (children at least 28 days but under one year)

4 The 'Non-occupied' category includes 'never worked, long-term unemployed, full-time students, inadequately described and unclassified for other reasons'. 
Figure $1 \quad$ Age specific mortality rates from all accidents by NS-SEC and age group, children aged $0^{1}-15,2001-03$

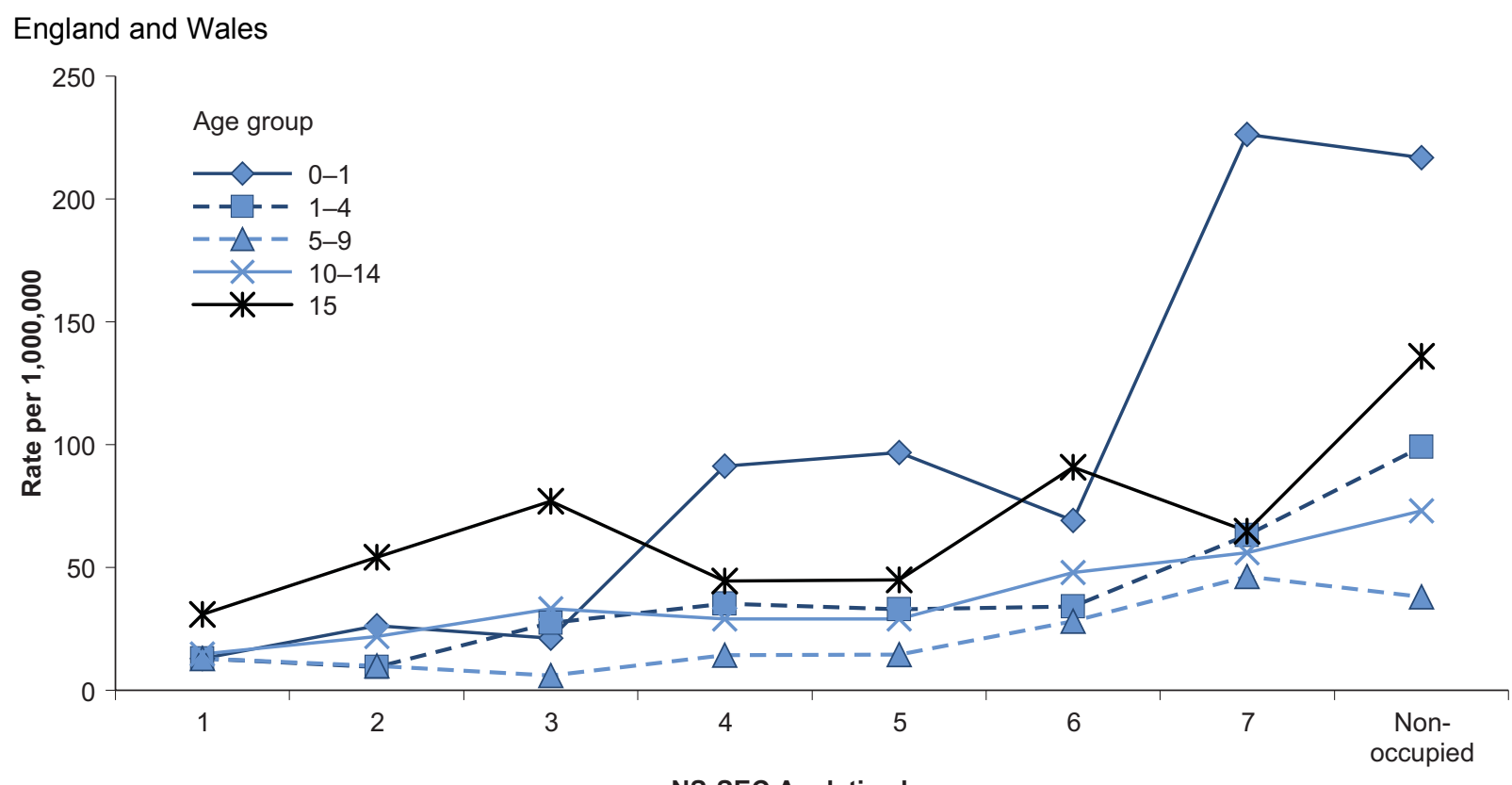

NS-SEC Analytic class

1 Deaths at age 0 only include postneonatal deaths (children at least 28 days but under one year) 


\section{Figure $2 \quad$ Age-specific mortality ratios ${ }^{1}$ from all accidents by age group, children aged $0^{2}-15,2001-03$}

England and Wales

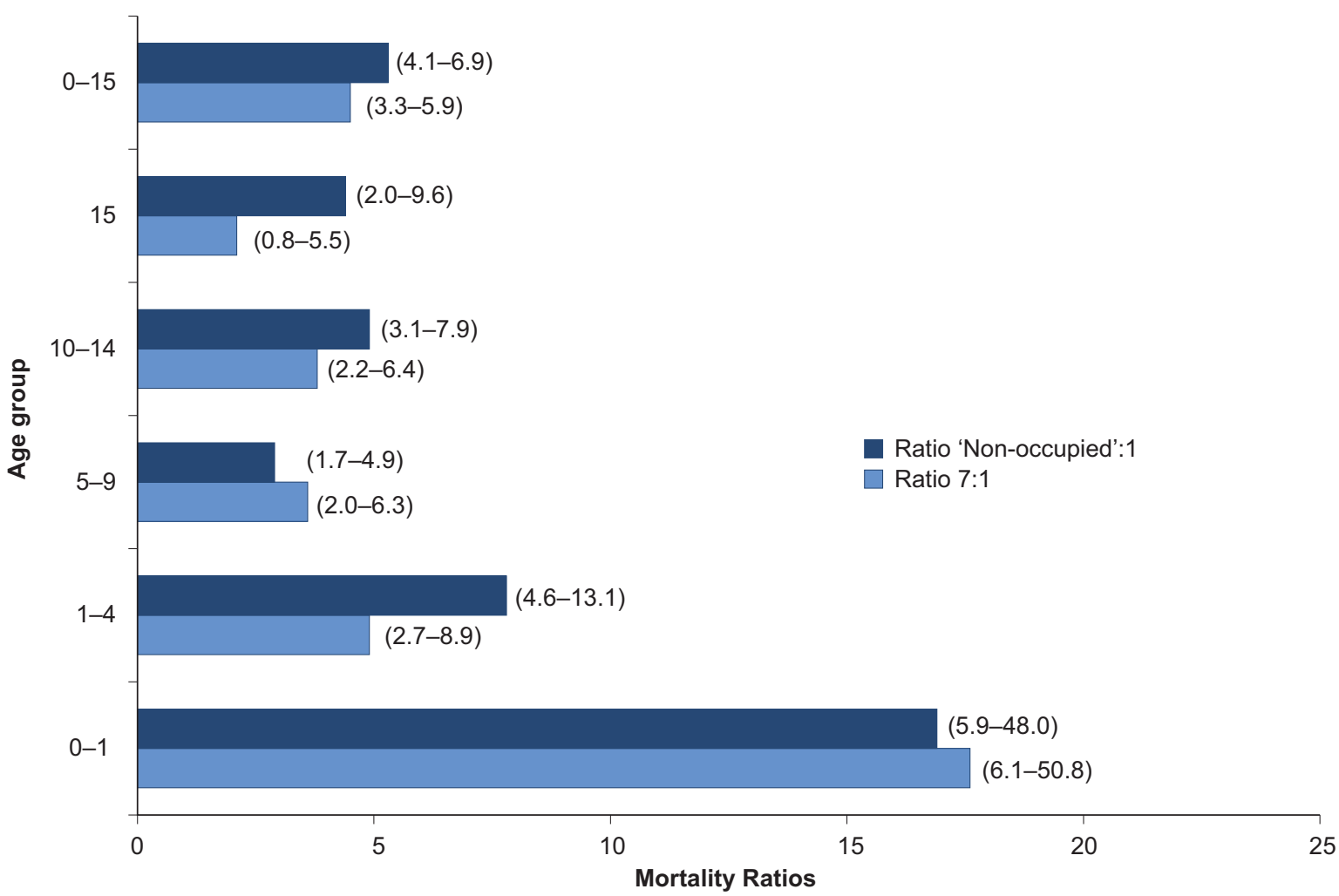

1 The mortality ratios are the ratios of mortality rates in NS-SEC class 7 and the 'Non-occupied' category respectively, to the mortality rate in NS-SEC class 1, for all accidents, 95 per cent Confidence Intervals shown in parenthesis 2 Deaths at age 0 only include postneonatal deaths (children at least 28 days but under one year)

The risk of accidental death for all children aged between 28 days and 15 years was significantly higher in the routine class (NS-SEC class 7) than in any other NS-SEC analytic classes, as seen in Table 3 . A child in the age group 28 days -15 years in the routine class had a risk of accidental death 4.5 times higher than a child with at least one parent in a higher managerial or professional occupation (95 per cent confidence interval: 3.3,5.9). However, the highest accidental mortality rate occurred when parents were classed as non-occupied (never worked, long-term unemployed, full-time students or unclassified) at 76 per million and was $5.3(4.1,6.9)$ times higher than the rate for those with at least one parent in the higher managerial and professional class (Table 3 and Figure 2).

Although the socio-economic patterns in accidental mortality within the different age bands mirrored in many respects that of all children between 28 days and 15 years, there were some age band-specific patterns (Figures 1 and 2, Table 3).

The highest accidental death rates among children occurred in infants aged at least 28 days but under one year, classified to the routine occupation class (226 per million). Infants in this age group in the routine class were $17.6(6.1,50.8)$ times more likely to die from an accident compared to children with at least one parent in the higher managerial/professional class (Table 3 ). The 
corresponding mortality ratio was similar when both parents were non-occupied, at $16.9(5.9,48.0)$. Consequently the socio-economic differences in accidental mortality were wider for this age group than for children at other ages, as shown in Figure 2.

Mortality rates from all accidents in the age group 5-9 were generally smaller than for younger or older children. The ratio of deaths between the parents in the non-occupied category and the higher managerial/professional class was more modest than in other age groups, at $2.9(1.7,4.9)$.

Mortality rates for children aged 15 years were generally higher across most analytical classes than other age groups, with the exception of the postneonatal age group (babies at least 28 days but under one year old). The mortality ratio between the routine and the higher managerial/professional classes was the lowest of all age groups, at $2.1(0.8,5.5)$. The accidental mortality rates for children aged 15 years with parents in the non-occupied group was particularly high at 136 per million with a mortality ratio of $4.4(2.0,9.6)$ compared to those with a parent in the most advantaged class.

\section{Age-specific mortality rates from selected accidental causes and from assault by NS-SEC}

Table 4 and Figure 3 enables comparison of the mortality rates of children aged from 28 days to 15 years across the selected causes of death in each of the NS-SEC analytic classes as well as in the non-occupied category. The relative sizes of the socio-economic gradients in mortality among causes of death are illustrated in Figure 4. 


\section{Table 4 Age-specific mortality rates ${ }^{1,2,3}$ from selected causes: by NS-SEC, children aged $0^{4}-15,2001-03$}

England and Wales

Rate per million

\begin{tabular}{|c|c|c|c|c|c|c|c|c|c|c|}
\hline \multirow{2}{*}{\multicolumn{2}{|c|}{ NS-SEC }} & \multicolumn{9}{|c|}{ Causes of death } \\
\hline & & All accidents & $\begin{array}{r}\text { Pedestrian } \\
\text { accidents }\end{array}$ & $\begin{array}{r}\text { Other } \\
\text { transport } \\
\text { accidents }\end{array}$ & Falls & Drowning & $\begin{array}{r}\text { Exposure to } \\
\text { Fire/Hot } \\
\text { Substances }\end{array}$ & Suffocation & $\begin{array}{r}\text { Other } \\
\text { Accidents }\end{array}$ & Assault \\
\hline \multirow[t]{2}{*}{1} & Higher managerial, & 14 & 2 & 6 & 1 & 1 & 1 & 2 & 2 & 2 \\
\hline & & $(11,18)$ & $(1,4)$ & $(4,8)$ & $(1,3)$ & $(1,3)$ & $(0,2)$ & $(1,4)$ & $(1,3)$ & $(1,3)$ \\
\hline \multirow[t]{2}{*}{1.} & Large employers, higher & 15 & 3 & 8 & - & - & - & - & 2 & 1 \\
\hline & & $(11,21)$ & $(1,6)$ & $(5,12)$ & - & - & - & - & $(1,5)$ & $(0,4)$ \\
\hline \multirow[t]{2}{*}{1.2} & Higher professionals & 14 & 2 & 3 & 2 & 2 & - & 3 & 2 & 2 \\
\hline & & $(10,19)$ & $(1,4)$ & $(2,7)$ & $(1,5)$ & $(1,5)$ & - & $(1,6)$ & $(1,4)$ & $(1,5)$ \\
\hline \multirow[t]{2}{*}{2} & Lower managerial, & 18 & 3 & 6 & 1 & 2 & 1 & 3 & 1 & 1 \\
\hline & & $(15,21)$ & $(2,5)$ & $(5,8)$ & $(0,2)$ & $(1,3)$ & $(0,2)$ & $(2,5)$ & $(1,2)$ & $(1,3)$ \\
\hline \multirow[t]{2}{*}{3} & Intermediate & 25 & 6 & 10 & 1 & 3 & 1 & 4 & - & 4 \\
\hline & & $(20,31)$ & $(4,9)$ & $(7,14)$ & $(0,3)$ & $(1,5)$ & $(1,3)$ & $(2,7)$ & - & $(3,7)$ \\
\hline \multirow[t]{2}{*}{4} & Small employers, own & 29 & 7 & 9 & - & 3 & - & 5 & 3 & 6 \\
\hline & & $(23,36)$ & $(4,11)$ & $(6,14)$ & - & $(2,7)$ & - & $(3,9)$ & $(1,6)$ & $(4,10)$ \\
\hline \multirow[t]{2}{*}{5} & Lower supervisory and & 30 & 7 & 8 & 2 & 3 & 1 & 5 & 3 & 5 \\
\hline & & $(24,38)$ & $(4,11)$ & $(5,13)$ & $(1,5)$ & $(2,7)$ & $(0,4)$ & $(3,9)$ & $(1,6)$ & $(3,8)$ \\
\hline \multirow[t]{2}{*}{6} & Semi-routine & 42 & 9 & 13 & 1 & 4 & 4 & 8 & 3 & 5 \\
\hline & & $(36,50)$ & $(6,13)$ & $(10,18)$ & $(0,2)$ & $(2,7)$ & $(3,7)$ & $(5,11)$ & $(2,6)$ & $(3,8)$ \\
\hline \multirow[t]{2}{*}{7} & Routine & 64 & 17 & 14 & 2 & 5 & 10 & 13 & 3 & 7 \\
\hline & & $(54,75)$ & $(13,24)$ & $(10,20)$ & $(1,6)$ & $(3,9)$ & $(6,15)$ & $(9,18)$ & $(1,6)$ & $(4,11)$ \\
\hline \multirow{2}{*}{\multicolumn{2}{|c|}{ 'Non-occupied'5 }} & 76 & 18 & 20 & 3 & 6 & 11 & 12 & 5 & 19 \\
\hline & & $(67,85)$ & $(14,23)$ & $(16,25)$ & $(2,5)$ & $(4,9)$ & $(8,15)$ & $(9,16)$ & $(3,8)$ & $(15,24)$ \\
\hline \multirow{2}{*}{\multicolumn{2}{|c|}{ All children }} & 33 & 7 & 10 & 1 & 3 & 3 & 6 & 2 & 5 \\
\hline & & $(31,35)$ & $(7,8)$ & $(9,11)$ & $(1,2)$ & $(3,4)$ & $(3,4)$ & $(5,7)$ & $(2,3)$ & $(5,6)$ \\
\hline \multirow{2}{*}{\multicolumn{2}{|c|}{ Ratio $7: 1$}} & 4.5 & 8.4 & 2.5 & 1.9 & 3.3 & 15.9 & 6.8 & 1.7 & 4.3 \\
\hline & & $(3.3,5.9)$ & $(4.2,17.0)$ & $(1.5,4.3)$ & $(0.6,6.2)$ & $(1.2,8.6)$ & $(4.8,53.5)$ & $(3.2,14.5)$ & $(0.6,4.9)$ & $(1.8,10.2)$ \\
\hline \multirow{2}{*}{\multicolumn{2}{|c|}{ Ratio 'Non-occupied':1 }} & 5.3 & 8.9 & 3.6 & 2.4 & 4.1 & 18.4 & 6.3 & 3.3 & 11.6 \\
\hline & & $(4.1,6.9)$ & $(4.6,17.3)$ & $(2.3,5.6)$ & $(0.9,6.5)$ & $(1.8,9.7)$ & $(5.7,59.3)$ & $(3.1,12.9)$ & $(1.4,7.5)$ & $(5.6,24.1)$ \\
\hline
\end{tabular}

1 Age-specific mortality rates along with 95 per cent Confidence Intervals shown below the rates in parenthesis.

2 Figures in table are rounded to nearest integer.

3 Age-specific mortality rates were not calculated where there were fewer than 3 deaths in a cell, denoted by a hyphen (-).

4 Deaths at age 0 only include postneonatal deaths (children at least 28 days but under one year).

5 The 'Non-occupied' category includes 'never worked, long-term unemployed, full-time students, inadequately described and unclassified for other reasons'. 


\section{Figure 3 Age-specific mortality rates from selected causes of accident and assault, by NS-SEC, children aged $0^{1}-15$, 2001-03}

England and Wales
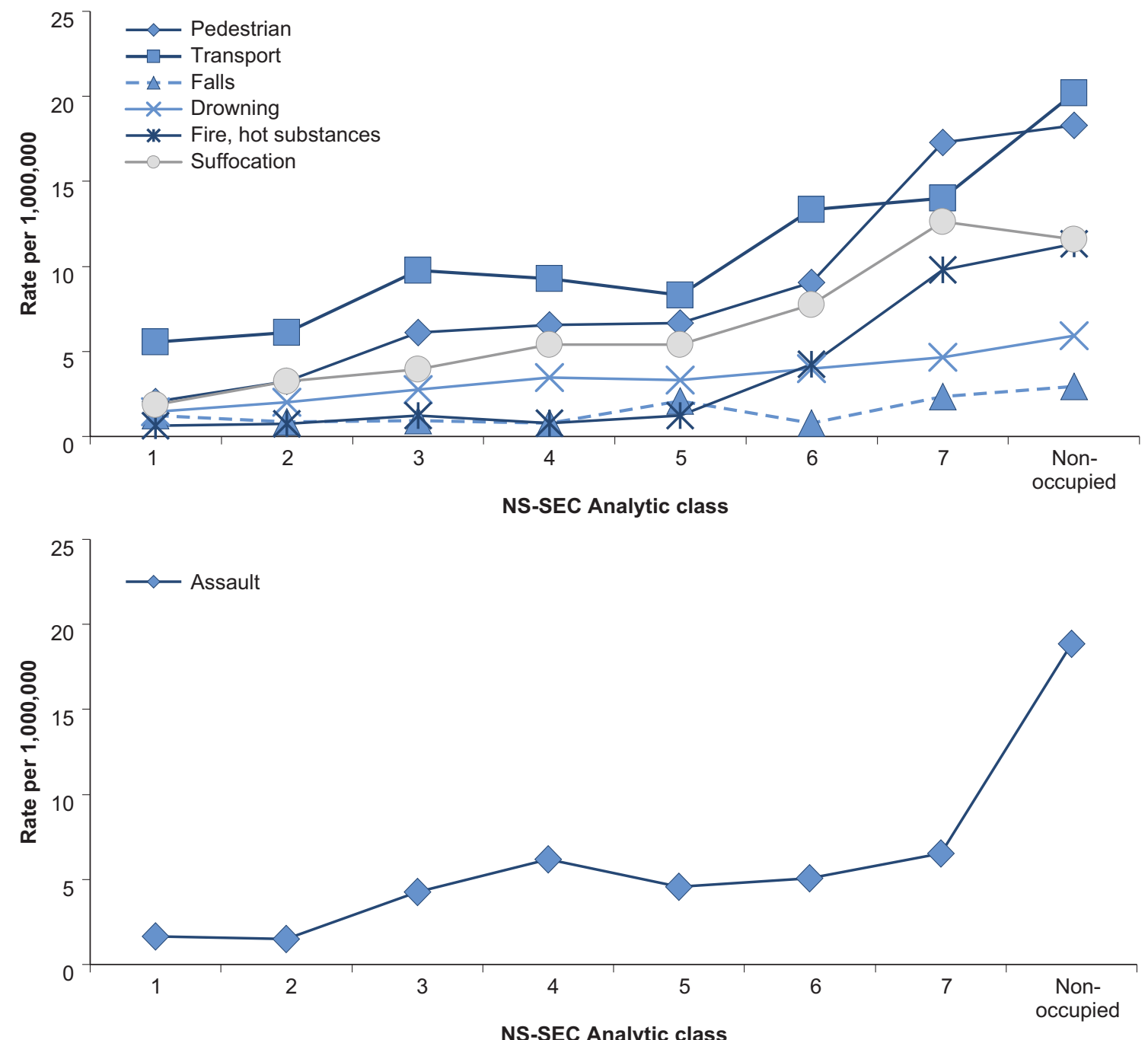

1 Deaths at age 0 only include postneonatal deaths (children at least 28 days but under one year) 


\section{Figure $4 \quad$ Age-specific mortality ratios ${ }^{1}$ from selected causes of accidents and assault, children aged $0^{2}-15,2001-03$}

England and Wales

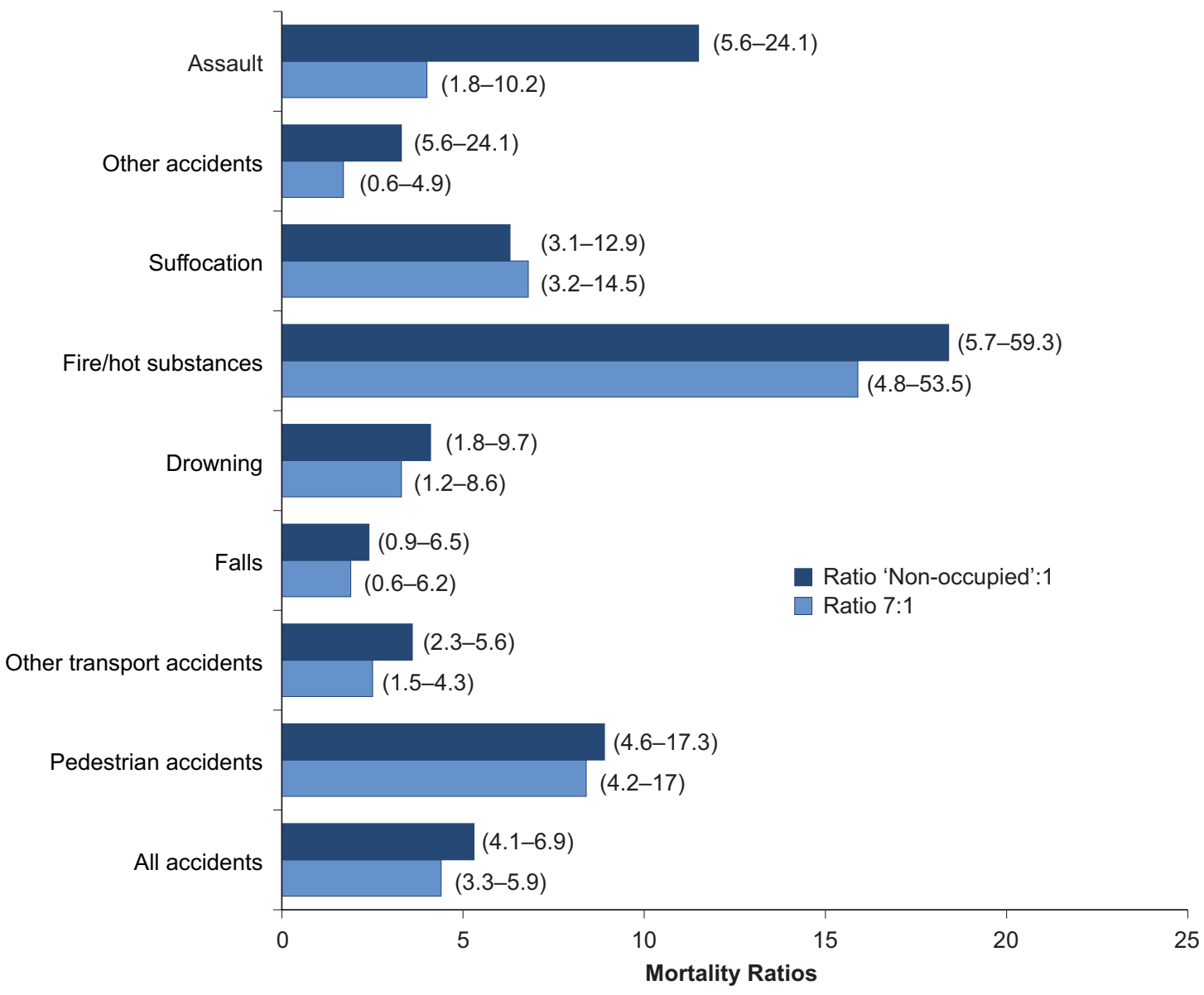

1 The mortality ratios are the ratios of mortality rates in NS-SEC class 7 and the 'Non-occupied' category respectively, to the mortality rate in NS-SEC class 1, for all accidents. 95 per cent Confidence Intervals shown in parenthesis 2 Deaths at age 0 only include postneonatal deaths (children at least 28 days but under one year)

Mortality rates from exposure to fire or hot substances contributed very little to death rates from accidents in the most advantaged NS-SEC analytic classes. However, owing to the high rates of death in the 'Routine' classes, as well as in the non-occupied category, this cause had the greatest socio-economic gradient in mortality taking all age groups of children together (15.9 and 18.4 respectively).

Suffocation and pedestrian accidents also showed large mortality ratios between NS-SEC classes 7 and 1 (6.8 and 8.4). For pedestrian accidents there was a significant difference in mortality rate between the routine and semi-routine classes.

The lowest socio-economic gradients in mortality were for drowning, transport accidents (excluding pedestrian accidents), falls and other accidents. In the latter two categories of accidents, children in the routine category did not have a significantly greater risk of death than children in the higher managerial/professional class. 
Deaths from assault had significant socio-economic gradients in mortality but there was a large difference between the rates for the routine class $(7$ per million $(4,11))$ and the non-occupied $(19$ per million $(15,24))$. The rate of mortality from assault in children aged between 28 days and 15 years was $11.6(5.6,24.1)$ times higher when parents were classed as non-occupied than when at least one parent was in the higher managerial and professional class.

\section{Mortality rates from selected accidental causes and from assault by condensed NS-SEC and by age group}

Mortality rates by condensed three-class NS-SEC and by age group for the different accidental causes of death are shown in Tables 5, 6 and 7. The condensed version has been used because of very small numbers of deaths in some classes when broken down by age group and cause.

\section{Pedestrian and other transport accidents}

Table 5 shows that for both pedestrian and other transport accident mortality rates increased with disadvantage. Inequalities in mortality, as evidenced by the socio-economic gradients, were more pronounced for pedestrian accidents than for other transport accidents, except at age 15, where there was no socio-economic gradient in mortality for pedestrian accidents. Inequalities in mortality tended to decrease with age for pedestrian accidents, but there appeared to be no age-related pattern in inequalities for other transport accidents (although their volume increased substantially with age). 


\section{Table 5 Age-specific mortality rates ${ }^{1,2}$ of children from all accidents, pedestrian and transport accidents: by 'reduced NS-SEC' and age group, 2001-03}

\begin{tabular}{|c|c|c|c|c|c|c|c|c|c|c|c|c|c|c|c|}
\hline \multirow[t]{2}{*}{ Reduced NS-SEC } & \multicolumn{15}{|c|}{ Age group } \\
\hline & \multicolumn{3}{|c|}{$0^{3}-4$} & \multicolumn{3}{|c|}{$5-9$} & \multicolumn{3}{|c|}{$10-14$} & \multicolumn{2}{|r|}{15} & \multicolumn{4}{|c|}{$0^{3}-15$} \\
\hline & All & Pedestrian & Transport & All & Pedestrian & ransport & All & Pedestrian & ransport & All & Pedestrian & ransport & All & Pedestrian & ransport \\
\hline 1 Managerial and & 13 & 1 & 2 & 11 & 2 & 5 & 20 & 4 & 8 & 46 & 11 & 18 & 16 & 3 & 6 \\
\hline & $(10,17)$ & $(1,3)$ & $(1,5)$ & $(8,15)$ & $(1,4)$ & $(3,8)$ & $(16,24)$ & $(2,6)$ & $(6,11)$ & $(33,64)$ & $(5,21)$ & $(11,31)$ & $(14,19)$ & $(2,4)$ & $(5,7)$ \\
\hline 2 Intermediate & 33 & 7 & 5 & 10 & 2 & 4 & 31 & 9 & 13 & 61 & 11 & 40 & 27 & 6 & 10 \\
\hline & $(25,43)$ & $(4,13)$ & $(3,10)$ & $(6,15)$ & $(1,5)$ & $(2,8)$ & $(24,40)$ & $(6,15)$ & $(9,19)$ & $(41,92)$ & $(4,28)$ & $(24,66)$ & $(23,31)$ & $(5,9)$ & $(7,12)$ \\
\hline $\begin{array}{l}3 \text { Routine and } \\
\text { Manual }\end{array}$ & 55 & 7 & 6 & 29 & 11 & 7 & 45 & 13 & 14 & 71 & 11 & 50 & 44 & 10 & 12 \\
\hline & $(46,65)$ & $(4,11)$ & $(4,10)$ & $(23,36)$ & $(7,16)$ & $(4,11)$ & $(37,53)$ & $(9,18)$ & $(11,20)$ & $(51,97)$ & $(5,25)$ & $(34,73)$ & $(40,49)$ & $(9,13)$ & $(10,15)$ \\
\hline \multirow[t]{2}{*}{ 'Non-occupied' } & 117 & 17 & 15 & 38 & 13 & 9 & 73 & 26 & 26 & 136 & 16 & 66 & 76 & 18 & 20 \\
\hline & $(96,141)$ & $(10,27)$ & $(9,26)$ & $(28,50)$ & $(8,20)$ & $(5,16)$ & $(60,89)$ & $(18,36)$ & $(19,37)$ & $(97,191)$ & $(6,44)$ & $(40,108)$ & $(67,85)$ & $(14,23)$ & $(16,25)$ \\
\hline \multirow[t]{2}{*}{ All children } & 38 & 5 & 5 & 19 & 6 & 6 & 36 & 10 & 13 & 67 & 12 & 38 & 33 & 7 & 10 \\
\hline & $(34,42)$ & $(4,7)$ & $(4,7)$ & $(16,22)$ & $(4,7)$ & $(4,7)$ & $(32,40)$ & $(8,12)$ & $(11,16)$ & $(57,80)$ & $(8,17)$ & $(30,47)$ & $(31,35)$ & $(7,8)$ & $(9,11)$ \\
\hline \multirow[t]{2}{*}{ Ratio 3:1 } & 4.2 & 5.8 & 2.6 & 2.6 & 5.4 & 1.4 & 2.3 & 3.4 & 1.8 & 1.5 & 1.1 & 2.7 & 2.7 & 3.8 & 2.0 \\
\hline & $(3.1,5.8)$ & $(2.2,15.8)$ & $(1.2,5.7)$ & $(1.8,3.8)$ & $(2.5,12.0)$ & $(0.7,2.6)$ & $(1.7,3.0)$ & $(1.9,6.3)$ & $(1.1,2.9)$ & $(1.0,2.4)$ & $(0.4,3.0)$ & $(1.4,5.2)$ & $(2.3,3.2)$ & $(2.5,5.5)$ & $(1.5,2.8)$ \\
\hline \multirow{2}{*}{$\begin{array}{l}\text { Ratio 'Non- } \\
\text { occupied':1 }\end{array}$} & 9.0 & 13.5 & 6.3 & 3.4 & 6.3 & 1.7 & 3.7 & 6.8 & 3.3 & 2.9 & 1.6 & 3.6 & 4.6 & 6.5 & 3.4 \\
\hline & $(6.5,12.5)$ & $(4.9,37.1)$ & $(2.8,14.2)$ & $(2.3,5.1)$ & $(2.7,14.8)$ & $(0.8,3.6)$ & $(2.8,5.0)$ & $(3.7,12.6)$ & $(2.0,5.3)$ & $(1.8,4.7)$ & $(0.5,5.2)$ & $(1.7,7.3)$ & $(3.9,5.5)$ & $(4.4,9.8)$ & $(2.5,4.7)$ \\
\hline
\end{tabular}

1 Age-specific mortality rates along with $95 \%$ Confidence Intervals shown below the rates in parenthesis

2 Figures in table are rounded to nearest integer

3 Deaths at age 0 only include postneonatal deaths (children at least 28 days but under one year)

4. The 'Non-occupied' category includes 'never worked, long-term unemployed, full-time students, inadequately described and unclassified for other reasons' 


\section{Accidents from Falls, Drowning or exposure to Fire/Hot substances.}

Table 6 shows that there was little difference between classes for deaths caused by falls, compared to other causes of accidental deaths.

The risk of death by drowning was consistently higher across all classes for children under five compared to children five years and over. Children whose parents were in the non-occupied group were significantly more at risk of death from drowning than those allocated to the managerial/professional class in both age groups 28 days -4 years and 5-15 years.

For mortality due to exposure to fire/hot substances, the socio-economic gradient in mortality was statistically significantly higher than the equivalent gradient for all accidents, with children aged from 28 days to 15 years in the routine/manual class being $6.9(3.3,14.2)$ times more at risk of death than children in the managerial/professional class. Those children allocated to the nonoccupied group had a particularly high mortality rate, and consequently a gradient of 16.2 . This high death rate for the non-occupied class was mainly driven by the rate of 28 per million in the age group 28 days -4 years. 


\section{Table $6 \quad$ Age-specific mortality rates ${ }^{1,2}$ of children from all accidents and accidents caused by falls, drowning or exposure to fire/hot substances: by 'reduced NS-SEC' and age group, 2001-03}

England and Wales

\begin{tabular}{|c|c|c|c|c|c|c|c|c|c|c|c|c|}
\hline $\begin{array}{l}\text { Reduced NS- } \\
\text { SEC }\end{array}$ & \multicolumn{12}{|c|}{ Age group } \\
\hline & \multicolumn{4}{|c|}{$0^{3}-4$} & \multicolumn{4}{|c|}{$5-15$} & \multicolumn{4}{|c|}{$0^{3}-15$} \\
\hline & All & Falls & Drowning & $\begin{array}{r}\text { Fire/Hot } \\
\text { Substances }\end{array}$ & All & Falls & Drowning & $\begin{array}{r}\text { Fire/Hot } \\
\text { Substances }\end{array}$ & All & Falls & Drowning & $\begin{array}{r}\text { Fire/Hot } \\
\text { Substances }\end{array}$ \\
\hline Managerial & 13 & 1 & 4 & 0 & 18 & 1 & 1 & 1 & 16 & 1 & 2 & 1 \\
\hline & $(10,17)$ & $(1,3)$ & $(2,6)$ & $(0,1)$ & $(15,21)$ & $(0,2)$ & $(0,2)$ & $(1,2)$ & $(14,19)$ & $(1,2)$ & $(1,3)$ & $(0,1)$ \\
\hline 2 Intermediate & 33 & 2 & 6 & 2 & 24 & 0.5 & 2 & 1 & 27 & 1 & 3 & 1 \\
\hline & $(25,43)$ & $(1,6)$ & $(3,11)$ & $(1,6)$ & $(20,29)$ & $(0,2)$ & $(1,4)$ & $(0,2)$ & $(23,31)$ & $(0,2)$ & $(2,5)$ & $(0,2)$ \\
\hline \multirow{2}{*}{$\begin{array}{l}\text { Routine and } \\
\text { Manual }\end{array}$} & 55 & 2 & 6 & 9 & 40 & 2 & 3 & 3 & 44 & 2 & 4 & 5 \\
\hline & $(46,65)$ & $(1,4)$ & $(4,10)$ & $(6,14)$ & $(35,46)$ & $(1,3)$ & $(2,5)$ & $(2,5)$ & $(40,49)$ & $(1,3)$ & $(3,6)$ & $(4,7)$ \\
\hline \multirow[t]{2}{*}{ 'Non-occupied' } & 117 & 3 & 14 & 28 & 62 & 3 & 3 & 6 & 76 & 3 & 6 & 11 \\
\hline & $(96,141)$ & $(1,10)$ & $(8,25)$ & $(19,41)$ & $(54,72)$ & $(1,6)$ & $(2,6)$ & $(4,10)$ & $(67,85)$ & $(2,5)$ & $(4,9)$ & $(8,15)$ \\
\hline \multirow[t]{2}{*}{ All children } & 38 & 2 & 6 & 6 & 30 & 1 & 2 & 2 & 33 & 1 & 3 & 3 \\
\hline & $(34,42)$ & $(1,3)$ & $(4,8)$ & $(4,7)$ & $(29,33)$ & $(1,2)$ & $(1,3)$ & $(2,3)$ & $(31,35)$ & $(1,2)$ & $(3,4)$ & $(3,4)$ \\
\hline \multirow[t]{2}{*}{ Ratio 3:1 } & 4.2 & 1.1 & 1.7 & $\approx 10.2$ & 2.2 & 1.9 & 3.3 & 3.0 & 2.7 & 1.6 & 2.2 & 6.9 \\
\hline & $(3.1,5.8)$ & $(0.3,4.1)$ & $(0.8,3.5)$ & $\approx(6.7,15.5)$ & $(1.8,2.7)$ & .7,5.1) & $(1.5,7.7)$ & $(1.3,6.6)$ & $(2.3,3.2)$ & $(0.7,3.3)$ & $(1.3,3.8)$ & $(3.3,14.2)$ \\
\hline \multirow{2}{*}{$\begin{array}{l}\text { Ratio 'Non- } \\
\text { occupied':1 }\end{array}$} & 9.0 & 2.2 & 3.9 & $\approx 30.5$ & 3.5 & 3.6 & 3.5 & 5.9 & 4.6 & 2.9 & 3.3 & 16.2 \\
\hline & $(6.5,12.5)$ & $(0.6,9.0)$ & $(1.9,8.2)$ & $\approx(20.6,45.1)$ & $(2.8,4.3)$ & $.3,9.9)$ & $(1.4,9.1)$ & $(2.6,13.3)$ & $(3.9,5.5)$ & $(1.3,6.5)$ & $(1.8,6.0)$ & $(7.9,33.2)$ \\
\hline
\end{tabular}

1 Age-specific mortality rates along with 95 per cent confidence Intervals shown below the rates in parenthesis

2 Figures in table are rounded to nearest integer

3 Deaths at age 0 only include postneonatal deaths (children at least 28 days but under one year)

4 The 'Non-occupied' category includes 'never worked, long-term unemployed, full-time students, inadequately described and unclassified for other reasons'

$\approx$ Ratios and confidence limits calculated using the top limit of the 95 per cent confidence interval instead of the rate for the managerial and professional class 


\section{Accidental suffocation}

The age-specific mortality rates from accidental suffocation by 'reduced NS-SEC' are reported in Table 7.

Accidental suffocation represented the main cause of death for postneonatal children: 67 per cent of accidental deaths for babies less than one year old were caused by suffocation. The socioeconomic gradient was also particularly high for this age group, at $8.5(4.0,18.2)$. The highest mortality rate caused by suffocation occurred for babies under one year whose parents were nonoccupied (142 per million), leading to a socio-economic gradient of $13.6(6.0,31.1)$.

Both mortality rates and social gradients were lower in other age groups. For those aged 5-9 there was no socio-economic gradient in mortality by suffocation. 


\section{Table 7 Age-specific mortality rates ${ }^{1,2}$ of children from all accidents, accidental suffocation, and assault, by 'reduced NS-SEC' and age group, 2001-03}

England and Wales

Rate per million

\begin{tabular}{|c|c|c|c|c|c|c|c|c|c|c|c|c|c|c|c|}
\hline \multirow[t]{3}{*}{ Reduced NS-SEC } & \multicolumn{15}{|c|}{ Age group } \\
\hline & \multicolumn{3}{|c|}{$0^{3}-1$} & \multicolumn{3}{|c|}{$1-4$} & \multicolumn{3}{|c|}{$5-9$} & \multicolumn{3}{|c|}{$10-15$} & \multicolumn{3}{|c|}{$0^{3}-15$} \\
\hline & All & Suffocation & Assault & All & Suffocation & Assault & All & Suffocation & Assault & All & Suffocation & Assault & All & Suffocation & Assault \\
\hline \multirow{2}{*}{$\begin{array}{l}1 \text { Managerial and } \\
\text { professional }\end{array}$} & 21 & 10 & 3 & 11 & 2 & 2 & 11 & 1 & 1 & 24 & 4 & 1 & 16 & 3 & 2 \\
\hline & $(13,34)$ & $(5,21)$ & $(1,10)$ & $(8,15)$ & $(1,4)$ & $(1,4)$ & $(8,15)$ & $(0,2)$ & $(1,3)$ & $(20,29)$ & $(3,6)$ & $(0,3)$ & $(14,19)$ & $(2,4)$ & $(1,2)$ \\
\hline \multirow[t]{2}{*}{2 Intermediate } & 45 & 28 & 14 & 30 & 4 & 4 & 10 & 1 & 6 & 36 & 5 & 4 & 27 & 5 & 5 \\
\hline & $(26,78)$ & $(14,56)$ & $(5,37)$ & $(22,41)$ & $(2,10)$ & $(2,9)$ & $(6,15)$ & $(0,4)$ & $(3,11)$ & $(29,45)$ & $(3,9)$ & $(2,8)$ & $(23,31)$ & $(3,7)$ & $(4,7)$ \\
\hline \multirow{2}{*}{$\begin{array}{l}3 \text { Routine and } \\
\text { Manual }\end{array}$} & 117 & 89 & 31 & 41 & 6 & 6 & 29 & 1 & 3 & 49 & 5 & 3 & 44 & 8 & 5 \\
\hline & $(89,155)$ & $(64,122)$ & $(18,54)$ & $(33,51)$ & $(3,11)$ & $(3,11)$ & $(23,36)$ & $(0,3)$ & $(2,7)$ & $(42,57)$ & $(3,9)$ & $(2,6)$ & $(40,49)$ & $(7,11)$ & $(4,7)$ \\
\hline \multirow[t]{2}{*}{ 'Non-occupied'4 } & 217 & 142 & 239 & 99 & 13 & 28 & 38 & 2 & 5 & 83 & 7 & 6 & 76 & 12 & 19 \\
\hline & $(151,312)$ & $(91,223)$ & $(169,338)$ & $(80,124)$ & $(7,24)$ & $(19,43)$ & $(28,50)$ & $(1,7)$ & $(3,12)$ & $(70,99)$ & $(4,13)$ & $(3,11)$ & $(67,85)$ & $(9,16)$ & $(15,24)$ \\
\hline \multirow[t]{2}{*}{ All children } & 67 & 45 & 32 & 32 & 4 & 6 & 19 & 1 & 3 & 41 & 5 & 3 & 33 & 6 & 5 \\
\hline & $(55,80)$ & $(36,56)$ & $(24,42)$ & $(28,36)$ & $(3,6)$ & $(5,8)$ & $(16,22)$ & $(1,2)$ & $(2,5)$ & $(37,45)$ & $(4,6)$ & $(2,4)$ & $(31,35)$ & $(5,7)$ & $(5,6)$ \\
\hline \multirow[t]{2}{*}{ Ratio 3:1 } & 5.6 & 8.5 & 11.9 & 3.7 & 4.1 & 2.9 & 2.6 & 1.0 & 2.3 & 2.1 & 1.4 & 2.9 & 2.7 & 3.1 & 3.4 \\
\hline & $(3.2,9.9)$ & $(4.0,18.2)$ & $(2.7,52.9)$ & $(2.5,5.5)$ & $(1.4,11.5)$ & $(1.1,7.4)$ & $(1.8,3.8)$ & $(0.2,6.2)$ & $(0.8,6.6)$ & $(1.6,2.6)$ & $(0.7,2.6)$ & $(1.0,8.4)$ & $(2.3,3.2)$ & $(2.0,4.6)$ & $(2.0,5.8)$ \\
\hline \multirow{2}{*}{$\begin{array}{l}\text { Ratio 'Non- } \\
\text { occupied':1 }\end{array}$} & 10.4 & 13.6 & 91.8 & 8.9 & 8.6 & 13.5 & 3.4 & 3.2 & 3.7 & 3.5 & 1.8 & 5.6 & 4.6 & 4.3 & 12.1 \\
\hline & $(5.6,19.1)$ & $(6.0,31.1)$ & $(22.0,383.1)$ & $(6.0,13.2)$ & $(2.9,25.1)$ & $(5.8,31.5)$ & $(2.3,5.1)$ & $(0.6,15.7)$ & $(1.2,11.0)$ & $(2.7,4.5)$ & $(0.9,3.8)$ & $(1.9,16.7)$ & $(3.9,5.5)$ & $(2.7,6.7)$ & $(7.4,19.9)$ \\
\hline
\end{tabular}

1 Age-specific mortality rates along with $95 \%$ Confidence Intervals shown below the rates in parenthesis

2 Figures in table are rounded to nearest integer

3 Deaths at age 0 only include postneonatal deaths (children at least 28 days but under one year)

4. The 'Non-occupied' category includes 'never worked, long-term unemployed, full-time students, inadequately described and unclassified for other reasons'. 


\section{Assaults}

Table 7 also shows the age-specific mortality rates for assault by 'reduced NS-SEC'.

The mortality of infants under one year old from assault had a large socio-economic gradient, compared to the other age groups analysed. This gradient was driven by a particularly high mortality rate from assault on post-neonatal infants allocated to the routine and manual class. The mortality rate of those in the non-occupied class was even higher at 239 per million $(169,338)$, which gave rise to a gradient of $92(22,383)$, the largest socio-economic inequality observed in this study.

The mortality rates for the older age bands were generally smaller, as were the socio-economic gradients. The exception was the mortality rate of those children aged 1-4 allocated to the nonoccupied group (at 28 per million). However, despite being high, this was significantly smaller than the mortality rate of the postneonatal non-occupied group.

The gradients and the mortality rates from assault were significantly lower in the age groups 5-9 and $10-15$ than in younger age groups.

\section{Discussion}

The mortality rate of children has fallen steadily since at least the 1970s, and the proportion of total deaths represented by accidents has also fallen. The 1970-72 occupational mortality decennial supplement (OPCS 1978) reported that there were just over 14,000 deaths of children 1-14 of which 33 per cent were accidents, poisonings or violence. In the current study, the number of deaths over a similar three-year period 2001-03 had reduced to 4,321, of which 18 per cent were accidents. However, accidents are still acknowledged as one of the substantial causes of death in children (The Audit Commission 2007). The Marmot Review (2010) also concluded that the single major avoidable cause of death in childhood in England was accidental death in the home for the under-fives and on the roads for the over-fives.

In the current study, accidental injury resulted in 1,016 deaths in children aged 28 days to 15 years during the period 2001-03. A further 164 deaths were attributed to assault. Our results show that although mortality rates for both accidents and assault have been decreasing overall, socioeconomic inequalities remain. Those children aged at least 28 days to 15 years in the routine class had a mortality rate 4.4 times that of those in the higher managerial and professional class. The mortality rate of those in the non-occupied group was even higher, being 5.3 times that in the higher managerial and professional class. Inequalities were particularly great for deaths caused by fire/exposure to hot substances, pedestrian accidents, accidental suffocation and assault among all children. The widest inequalities in fatal accidents for individual age groups occurred for infants aged at least 28 days but under one year. The steepest socio-economic gradients found for any age-group and cause resulted from assault on infants in the non-occupied group, however the small numbers involved mean that these results should be treated with some caution. 


\section{Comparisons with previous work}

Direct comparison of historical data with data in this analysis is difficult due to the changes in reporting that have occurred. The 10th revision of the International Classification of Diseases (ICD10) was implemented in 1994, following the ICD-9 used for mortality statistics in the previous two decades.

From 2001, the National Statistics Socio-economic Classification (NS-SEC) replaced Social Class based on occupation (formerly the Registrar General's Social Class) for mortality statistics. Early studies of childhood mortality were based on the father's social class only (OPCS, 1978). Others included the mother's social class when the father's social class was unknown (Edwards et al., 2006). The children in the current study are assigned to the NS-SEC of the biological or adoptive parent with the most favourable labour market position and employment status. The choice to take account of the mother's own socio-economic position reflects the changes that happened over the last 30 years, with a very high percentage of working mothers in the 21 st century. The most favourable socio-economic position of the parents is likely to have a direct impact on the environment of a child, whether it derives from the mother or the father.

The 1970-72 Occupational Mortality Decennial Supplement (OPCS, 1978) found that there were marked socio-economic effects in the mortality rate for all types of accidents. Overall, children in Social Class $\mathrm{V}$ had a mortality rate from accidents, poisonings and violence about four times that of Social Class I in 1970-72. That study also reported particularly high gradients for falls, fire and drowning for which the Social Class $\vee$ rates for males was more than ten times that of Social Class I.

The Occupational Mortality Decennial Supplement covering four years around the 1981 Census (OPCS, 1988) demonstrated similar high gradients for all accidents, and pointed out particularly high gradients for fire and pedestrian accidents for children under 10 years.

Roberts and Power (1996), using data from ONS, compared mortality rates from the early 1980s with that from the early 1990s. They concluded that socio-economic inequalities in rates of mortality from accidents and injury for children aged between 0 and 15 years increased during the 1980s. The ratio of mortality rates between social classes $V$ and I increased from about 3.5 to 5.0 . This increase was largely a result of the lack of improvement in social class $V$. They also reported that accidental death had increased as a proportion of all childhood deaths as a result of the rapid decline in deaths from non-external causes.

More recently Edwards et al. (2006) studied trends in socio-economic inequalities from the 1980 s to the period 2001-03. They found similar results to Roberts and Power (1996) for the 1980s and 1990s and for 2001-03 the ratio of mortality rates of the routine to higher professional and managerial classes for children between 0 and 15 years was of the order of 5.0/1.9 =2.6, which compares to the gradient in this study of $4.4(3.3,5.9)$. Their results are not directly comparable with the results presented here for a number of reasons.

Firstly, Edwards et al. (2006) classified children according to the father's socio-economic class, and then the mother's if the father's was unavailable. It is to be expected that the gradient based on the 'combined' NS-SEC should be larger. Such combined classifications have in other studies 
been found to be better socio-economic discriminators of mortality (Erikson, 2006). In essence, those classified as routine under the combined classification will be a smaller group, omitting those whose mothers belong to a family with a more advantaged class, and thus would be more likely to be materially disadvantaged.

Secondly, the earlier study used death occurrences (that is, selection of deaths by the date of death) rather than registrations, and included some cause of death codes and excluded others in their definition of injury and poisoning that are not used in this current analysis.

In summary, although mortality rates for accidental injury in children have fallen considerably since the 1970s and the proportion of accidental deaths in total childhood deaths has also fallen, accidents are still one of the leading causes of death in children. Although exact comparisons with previous studies are not possible, it appears that substantial socio-economic inequalities remain in this area, particularly for the post-neonatal group (babies at least 28 days but under one year old).

The trend in death from assault is difficult to determine, owing to changes over time in the classifications of cause of death, and the time taken to reach a verdict on a number of cases. However in the current study, a very steep social gradient exists with children from the nonoccupied group experiencing a rate of mortality from assault around 12 times those in the managerial and professional class. The mortality rate for those in the non-occupied group is particularly high.

The total disability and morbidity resulting from accidents is large. The Audit Commission (2007) stated that accidental injury resulted in approximately two million A\&E visits each year by children under the age of 14 . Since accidents might be more easily preventable than chronic disease deaths, it could be argued that reducing accidental deaths among more disadvantaged children would be an effective and timely approach to reducing social class differences in mortality and years of potential life lost.

Reducing the large inequalities between the most advantaged class and the most disadvantaged group, the non-occupied category, would make a substantial impact on childhood deaths from accidents and assaults. If the mortality rates in the latter group were the same as in the 'managerial and professional' class, deaths of infants under one year from assault would be reduced by 62 per cent. Deaths from fire, accidental suffocation and pedestrian accidents in the under-fives would be reduced by 50 per cent, 25 per cent and 28 per cent respectively. Deaths in pedestrian and transport accidents for children aged $5-15$ would be reduced by 24 per cent and 16 per cent respectively.

\section{Limitations}

Historically, in studies of childhood mortality by socio-economic groups, ONS has typically focused on those children whose parents can be classified according to social class. There is a substantial group of children for whom neither parent can be classified to an occupation. It was reported in a paper by Judge and Benzeval (1993) that children in the unoccupied class have the worst mortality of all social groups for all causes of death, and that the unoccupied class largely consists of economically inactive single mothers. 
The current study clearly indicates that children whose parents are not classified according to an occupation had consistently higher mortality rates than children with at least one parent with an occupation, for all causes of accidental death studied and for assault. However, there is no distinction made in the current work between unoccupied and inadequately described categories, who may have a different mortality pattern, as suggested by Judge and Benzeval (1993). The nonoccupied in the current study encompass a broad range of parents, including those who are longterm unemployed or have never worked (the unoccupied); full-time students; those whose occupations were either not given or inadequately described for classification purposes; or whose occupations were not classifiable for other reasons.

The population of children whose parents are not classified according to an occupation (the nonoccupied) accounts for 12 per cent of all children of which 69 per cent are living with a single parent, mostly with a single mother. In this study, 28 per cent of all accidental deaths reported for children in the non-occupied category did not have any recorded information on the father's occupation and 66 per cent of all accidental deaths for children in the non-occupied category were of children with both parents having an occupation not stated, inadequately described or not classifiable for other reasons. However, it is not possible to identify from death registrations how many child deaths in the non-occupied category were of children living with a single parent. Indeed, the occupation of both biological or adoptive parents could be recorded even if the child was living with only one of the biological or adoptive parents. Children of single parents in the nonoccupied class are likely to be at higher risk of accidental death or death from assault than other children, as previously suggested by Judge and Benzeval (1993). However, this work cannot prove this fact with certainty.

The population of children classified according to the parental socio-economic classes in the period 2001-03 was based on the 2001 Census. Therefore this study does not take account of any change in the composition of the population, social mobility or population growth during the period 2001-03.

Only the socio-economic class of the biological or adoptive parent was taken into account. This might have introduced a bias as it does not necessarily reflect the contribution of step-parents to the material circumstances of the family.

The age range chosen was limited to 28 days -15 years, since above the age of 15 the person's own occupation rather than the parental occupation is recorded at death registration. Also, at death registration, the father's last full-time employment is recorded. Therefore if the father is long-term unemployed after a period of employment, this will not appear on the child death certificate, as it would at census.

In some of the findings presented the number of underlying deaths was small, leading to wide confidence intervals. This may lead to a degree of uncertainty in the interpretation of the resultant socio-economic gradients. However, the authors have been careful not to draw stronger conclusions than seem merited by the estimates. 


\section{Conclusions}

This analysis presents age specific mortality rates by combined NS-SEC for selected accidents and assaults among children age at least 28 days to 15 years in England and Wales in the period 2001-03. It confirms results from previous studies showing a general pattern of steady decline in mortality from accidents and assaults. However, the results also showed that a substantial and clear social gradient in child mortality arising from accidents and assault persisted.

The study found that children aged 28 days to 15 years in the routine class had a mortality rate from accidents 4.4 times that of those in the higher managerial and professional class. Those children whose parents could not be allocated an occupied NS-SEC class had an even higher mortality rate, more than five (5.3) times the rate of the more advantaged children.

There were differences in socio-economic gradients by both cause of death and age group. The steepest socio-economic gradients observed for all childhood accidents was for those over 28 days but under one year old, the post-neonatal group. Considering accident type for all children, the highest socio-economic gradients were for fire and pedestrian accidents, followed by accidental suffocation. Assault for children whose parents could not be allocated an occupied NS-SEC class also had a very high gradient. The socio-economic gradient for accidental suffocation was highest for children less than one year old, while the gradients for death by exposure to fire, flame or hot substances were higher for those under five than for older children.

Childhood accidental mortality is acknowledged as the tip of the iceberg of the total harm done to children by accidents and assaults, with much disability and morbidity for each death, and childhood accident mortality has a disproportionate impact on years of potential life lost. This analysis seems to suggest that reducing inequalities in pedestrian accidents in children under fifteen and accidental suffocation, accidental exposure to fire/hot substances and assault for the under-fives, and particularly those under one year, would have the largest impact on narrowing the existing social inequalities in fatal childhood accidents and assaults.

\section{Acknowledgements}

The authors would like to thank Brian Johnson, Ann Langford, Julie Messer and Tom Powell for their great help towards this study. 


\section{References}

The Audit Commission (2007) Better safe than sorry, Preventing unintentional injury to Children. Health National report. London. Available on the Audit Commission website at: www.auditcommission.gov.uk/nationalstudies/health/publichealth/pages/bettersafethansorry.aspx

Bellis M A, Hughes K, Anderson Z, Tocque K, Hughes S (2008) Contribution of violence to health inequalities in England: demographics and trends in emergency hospital admissions for assault, Journal of Epidemiol Community Health 62:1064-1071 .

Black D, Morris J, Smith C and Townsend P (1980) Inequalities in health: report of a research working group. The Black Report, Department of Health and Social Security: London.

Department of Health (1999) Saving Lives: Our healthier Nation. White Paper presented to Parliament by the Secretary of State for Health by Command of Her Majesty. TSO: London. Available online at: [ARCHIVED CONTENT] Saving lives: Our Healthier Nation : Department of Health - Publications

Department of Health (2002) Preventing Accidental Injury - Priorities for Action. Report to the Chief Medical Officer from the Accidental Injury Task Force. TSO: London. Available on the Department of Health website at:

www.dh.gov.uk/en/Publicationsandstatistics/Publications/PublicationsPolicyAndGuidance/DH 406 $\underline{4841}$

Edwards P, Green J, Roberts I and Lutchmun (2006) 'Deaths from injury in children and employment status in family: analysis of trends in class specific death rates' British Medical Journal 333 (7559), 119-21.

Erikson R (1984) 'Social class of men, women and families', Sociology, 18, 500-14

Erikson R (2006) 'Social class assignment and mortality in Sweden', Social Science in Medicine 62 (9), 2151-160.

Grayling T, Hallam K, Graham DJ, Anderson R and Glaister S (2002) Streets ahead: safe and liveable streets for children, Institute for Public Policy Research, London.

Judge K and Benzeval M (1993) Health Inequalities: new concerns about the children of single mothers. British Medical Journal 306, 677-680.

Langford A. and Johnson B. (2009) Social inequalities in adult female mortality by the National Statistics Socio-Economic Classification, England and Wales, 2001-03. Health Statistics Quarterly 42, 6-21. Available on the Office for National Statistics website at: www.statistics.gov.uk/articles/hsq/HSQ42-Inequality-female-mortality.pdf

The Marmot Review (2010). Fair Society, Healthy Lives: Strategic Review of Health Inequalities in England post-2010. Available on line at: www.marmotreview.org/ 
Office for National Statistics (2007) The National Statistics Socio-Economic Classification on-line edition. Available on the Office for National Statistics website:

www.statistics.gov.uk/statbase/product.asp?vlnk=13561

Office for National Statistics (2008), Mortality Statistics: Deaths registered in 2006, Review of the Registrar General on deaths in England and Wales.

Office of Population, Censuses and Surveys (1978) Occupational mortality: The Registrar General's decennial supplement for England and Wales 1970-72, Her Majesty's Stationery Office: London.

Office of Population, Censuses and Surveys (1988) Occupational mortality: childhood supplement: The Registrar General's decennial supplement for England and Wales 1979-80, 1982-83, Her Majesty's Stationery Office: London.

Roberts I and Power C (1996) 'Does the decline in child injury mortality vary by social class? A comparison of class specific mortality in 1981 and 1991' British Medical Journal 313, 784-786.

Rooney C and Devis T (1999) 'Recent trends in deaths from homicide in England and Wales', Health Statistics Quarterly 03, 5-13. Available on the Office for National Statistics website at: www.statistics.gov.uk/articles/hsq/HSQ3Homicide.pdf

Rose D and Pevalin D (eds) (2003). A Researcher's Guide to the National Statistics SocioEconomic Classification, Sage: London.

World Health Organization, Galan A and Farchi S (2007) Mortality in children and adolescents from unintentional injuries (falls, drowning, fires and poisoning), ENHIS, fact sheet number 2.2. Available on the World Health Organization website at: www.euro.who.int/ data/assets/pdf file/0009/97830/ENHIS Factsheet 2 2.pdf 